\title{
A HIGH-PERFORMANCE LIQUID CHROMATOGRAPHY-MASS SPECTROMETRY METHOD DEVELOPMENT FOR THE QUANTITATIVE DETERMINATION OF ENALAPRIL MALEATE FROM CACO-2 CELL MONOLAYERS
}

\author{
LILIYA LOGOYDA* \\ Department of Pharmaceutical Chemistry, Pharmaceutical Faculty, I. Horbachevsky Ternopil State Medical University, Ternopil City, \\ Ukraine. Email: logojda@tdmu.edu.ua
}

Received: 24 February 2018, Revised and Accepted: 13 March 2018

\section{ABSTRACT}

Objective: A simple, rapid high-performance liquid chromatography-mass spectrometry (HPLC MS/MS) method was developed for the determination of enalapril maleate from confluent Caco-2 monolayers and aqueous solution.

Methods: Chromatography was achieved on Discovery C18, 50×2.1 mm, $5 \mu \mathrm{m}$ column. Samples were chromatographed in a gradient mode (eluent A [acetonitrile-water-formic acid, 5: 95:0.1 v/v] and eluent B [acetonitrile-formic acid, 100:0.1 v/v]). The initial content of the eluent B is 0\%, which increases linearly by $1.0 \mathrm{~min}$ to $100 \%$ and $1.01 \mathrm{~min}$ returns to the initial $0 \%$. The mobile phase was delivered at a flow rate of $0.4 \mathrm{ml} / \mathrm{min}$ into the mass spectrometer ESI chamber. The sample volume was $5 \mu$ l.

Results: Under these conditions, enalapril maleate was eluted at $1.52 \mathrm{~min}$. According to the Caco- 2 test results, enalapril showed low permeability. It should be noted that the recovery value for enalapril is $100.62 \%$. Low in vitro permeability data for enalapril are in good agreement with the literature data.

Conclusion: From results of the analysis, it can be concluded that developed method is simple and rapid for determination of enalapril maleate from confluent Caco-2 monolayers and aqueous solution. Acquired results demonstrate that proposed strategy can be effortlessly and advantageously applied for examination of enalapril from Caco-2 cell monolayers.

Keywords: High-performance liquid chromatography-mass spectrometry, Enalapril maleate, Caco-2 cells, Recovery, Bioavailability.

(c) 2018 The Authors. Published by Innovare Academic Sciences Pvt Ltd. This is an open access article under the CC BY license (http://creativecommons. org/licenses/by/4. 0/) DOI: http://dx.doi.org/10.22159/ajpcr.2018.v11i7.25455

\section{INTRODUCTION}

Enalapril maleate is chemically described as (2S)-1-[(2S)-2[[(1S)-1-(Ethoxycarbonyl)-3-phenylpropyl] amino] propanoyl] pyrrolidine-2- carboxylic acid (Z)-butenedioate (Fig. 1). Enalapril maleate is a prodrug which metabolized rapidly in the liver to ethyl ester of a long-acting enalaprilat, which inhibits angiotensin-converting enzyme in human subjects and animals. In the contemporary literature, bioanalytical methods were reported for quantification of enalapril [1-4]. However, methods are not developed for examination of enalapril maleate from Caco-2 cell monolayers.

Therefore, the aim of this study was to develop and validate an efficient high-performance liquid chromatography-mass spectrometry (HPLC MS/MS) method for the determination of enalapril maleate from Caco-2 cell monolayers.

\section{METHODS}

Chemicals and reagents

Trypsin EDTA (10x) 0.5\%/0.2\% in DPBS (PAA, UK; Cat\# L11-003)

HEPES, High Purity Grade (Helicon, Am-0485)

Dulbecco's PBS (1x) without Ca and Mg (PAA, UK; Cat\# H15-002)

Hanks' BSS (1x) without Ca and Mg without Phenol Red (PAA, UK; Cat\# H15-009)

DMSO Chromasolv Plus, HPLC grade, $\geq 99.7 \%$ (Sigma-Aldrich, USA; Cat \#34869)
DMEM (4.5g/l) liquid without L-Glutamine (PAA, UK; Cat\# E15-009)

L-Glutamine (200 mM) (PAA, UK; Cat\# M11-004)

Fetal Bovine Serum “GOLD” EU approved (PAA, UK; Cat\# A15-151)

Penicillin/Streptomycin (100x) (PAA, UK; Cat\# P11-010)

Acetonitrile Chromasolv, gradient grade, for HPLC, $\geq 99.9 \%$ (SigmaAldrich, USA; Cat \#34851)

Formic acid for mass spectrometry, 98\% (Fluka, USA; Cat \#94318)

Falcon® HTS 24-Multiwell Insert Systems with Media Feeder Tray (BD Biosciences, USA; Prod\# 351181)

Falcon ${ }^{\circledR} 24$ Well TC-Treated Cell PS Permeable Support Companion Plate (BD, Prod\# 353504)

Centrifuge Tubes, 50 ml (Santa Cruz, USA; Cat\# sc-200251)

Serological Pipettes $5 \mathrm{ml}, 10 \mathrm{ml}$, and $25 \mathrm{ml}$ (Greiner Bio-One)

Disposable pipettor tips (Thermo Scientific, Fisherbrand, and Eppendorf USA)

$1.1 \mathrm{ml}$ microtubes in microracks (Thermo Scientific, USA)

Zorbax Eclipse Plus C18 column $2.1 \times 50 \mathrm{~mm}, 3.5 \mu \mathrm{m}$ (Agilent Technologies, Inc. USA) 
Propranolol hydrochloride $\geq 99 \%$ (TLC), powder (Sigma-Aldrich, USA; Cat \# P0884)

Quinidine anhydrous (Sigma-Aldrich, USA; Cat \# Q3625 Lot \#BCBF1345V

Atenolol, analytical reference material, $\geq 98.5 \%$ (HPLC) (Sigma-Aldrich, USA; Cat \#74827)

The test compound was provided as a dry powder (salt form enalapril maleate) and was dissolved in DMSO at $10 \mathrm{mM}$ to prepare working stocks.

\section{Instrumentation and chromatographic conditions}

All measurements were performed using Shimadzu VP HPLC system including vacuum degasser, gradient pumps, reverse phase HPLC column, column oven, and autosampler. The HPLC system was coupled with tandem mass spectrometer API 3000 (PE Sciex). The TurbolonSpray ion source was used in both positive and negative ion modes. Parameters of electrospray ionizer and MRM parameters are listed in Tables 1 and 2. Acquisition and analysis of the data were performed using Analyst 1.5.2 software (PE Sciex). Chromatography was achieved on DiscoveryC18, 50×2.1 mm, and $5 \mu \mathrm{m}$ column. Samples were chromatographed in a gradient mode (eluent A [acetonitrile-water-formic acid, 5:95:0.1 v/v] and eluent B [acetonitrile-formic acid, 100:0.1 v/v]). The initial content of the eluent $\mathrm{B}$ is $0 \%$, which increases linearly by $1.0 \mathrm{~min}$ to $100 \%$ and $1.01 \mathrm{~min}$ returns to the initial $0 \%$. The mobile phase was delivered at a flow rate of $0.400 \mathrm{ml} / \mathrm{min}$ into the mass spectrometer ESI chamber. The sample volume was $5 \mu \mathrm{l}$.

Caco- 2 cells were cultivated in $75 \mathrm{~cm}^{2}$ flasks to $70-80 \%$ of confluence according to the ATCC and Millipore recommendations [5] in a humidified atmosphere at $37^{\circ} \mathrm{C}$ and $5 \% \mathrm{CO}_{2}$. Cells were detached with Trypsin/EDTA solution and resuspended in the cell culture medium to a final concentration of $2 \times 10^{5}$ cells $/ \mathrm{ml} .500 \mu \mathrm{l}$ of the cell suspension was added to each well of HTS 24-Multiwell Insert System, and $35 \mathrm{ml}$ of prewarmed complete medium was added to the feeder tray. Caco2 cells were incubated in Multiwell Insert System for 21 days before the

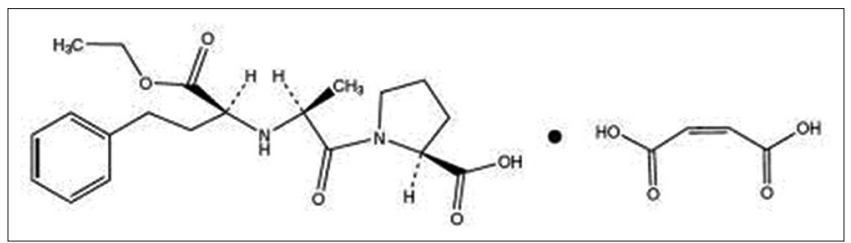

Fig. 1: Chemical structure of enalapril maleate

Table 1: Parameters of ionizer electrospray

\begin{tabular}{lll}
\hline S.no & Parameter & Value \\
\hline 1 & Polarity & Positive \\
2 & Nebulizer Gas (NEB, Gas 1) & 15 \\
3 & Curtain Gas (CUR) & 8 \\
4 & Collision Gas (CAD) & 4 \\
5 & IonSpray Voltage (IS) & 5000 \\
6 & Temperature (TEM) & 400 \\
7 & Turbo IonSpray Gas & 8 \\
8 & Horizontal Position & 5.3 \\
9 & Lateral Position & 1.3 \\
\hline
\end{tabular}

transport experiments. The medium in filter plate and feeder tray was changed every other day. After 21 days of cell growth, the integrity of the monolayer was verified by measuring the transepithelial electrical resistance (TEER) for every well using the Millicell-ERS system ohm meter. The final TEER values were within the range 150-600 $\Omega \times \mathrm{cm}^{2}[6]$ as required for the assay conditions. 24-well insert plate was removed from its feeder plate and placed in a new sterile 24-well transport analysis plate. The medium was aspirated and inserts washed with PBS twice.

To determine the rate of compounds transport in apical (A) to basolateral (B) direction, $300 \mu \mathrm{L}$ of the test compound dissolved in transport buffer at $10 \mu \mathrm{M}$ (HBSS, $10 \mathrm{mM}$ HEPES, and $\mathrm{pH}=7.4$ ) was added into the filter wells; $1000 \mu \mathrm{L}$ of buffer (HBSS, $10 \mathrm{mM}$ HEPES, and $\mathrm{pH}=7.4$ ) was added to transport analysis plate wells. The plates were incubated for $90 \mathrm{~min}$ at $37^{\circ} \mathrm{C}$ with shaking at $100 \mathrm{RPM}$. $75 \mu \mathrm{L}$ aliquots were taken from the donor and receiver compartments for LC-MS/MS analysis. All samples were mixed with 2 volumes of acetonitrile with following protein sedimentation by centrifuging at $10,000 \mathrm{rpm}$ for $10 \mathrm{~min}$. Supernatants were analyzed using the HPLC system coupled with tandem mass spectrometer.

Propranolol (high permeability), Atenolol (low permeability), and Quinidine (moderate permeability) were used as reference compounds.

The apparent permeability $\left(\mathrm{P}_{\text {app }}\right)$ was calculated for Caco-2 permeability assay using the following equation:

$\mathrm{P}_{\text {app }} \frac{\mathrm{V}_{\mathrm{A}}}{\text { Area }} \times \frac{[\mathrm{drug}]_{\mathrm{acc}}}{[\mathrm{drug}]_{\text {initialdonar }}}$

$\mathrm{V}_{\mathrm{A}}$ - volume of transport buffer in acceptor well,

Area - surface area of the insert (equals to effective growth area of the insert $-0.31 \mathrm{~cm}^{2}$,

Time - time of the assay,

[drug $]_{\text {acc }}$ - concentration of test compound in acceptor well,

$[\mathrm{drug}]_{\text {initiald }}-$ initial concentration of test compound in a donor well. $\mathrm{P}_{\text {app }}$ is expressed in $10^{-6} \mathrm{~cm} / \mathrm{s}$.

The percentage recovery can be useful in interpreting the Caco-2 data. If the recovery is very low, this may indicate problems with poor solubility, binding of the compound to the test plate materials, metabolism by the Caco-2 cells, or accumulation of the compound in the cell monolayer. The percentage recovery was calculated using the following equation:

$\%$ recovery $=\frac{\mathrm{C}_{\mathrm{acc}} \times \mathrm{V}_{\mathrm{acc}}+\mathrm{C}_{\mathrm{d}} \times \mathrm{V}_{\mathrm{d}}}{\mathrm{C}_{\text {initial,d }}} \times 10 \mathrm{C}$,

$\mathrm{V}_{\text {acc }}$ - volume of compound solution in acceptor well $\left(\mathrm{cm}^{2}\right)$,

$\mathrm{V}_{\mathrm{d}}$ - volume of compound solution in donor well $\left(\mathrm{cm}^{2}\right)$

$\mathrm{C}_{\text {acc }}$ - concentration of test compound in acceptor well $(\mu \mathrm{M})$,

$\mathrm{C}_{\text {initial,d }}$ - initial concentration of test compound in a donor well $(\mu \mathrm{M})$.

\section{RESULTS AND DISCUSSION}

In the present study, optimization and critical evaluation of mobile phase composition, flow rate, and analytical column were important to obtain good resolution of peaks of interest from the endogenous components, which, in turn, affect reproducibility and sensitivity of the method [7-13]. The resolution of peaks was best achieved with Discovery C18, $50 \times 2.1 \mathrm{~mm}$, and $5 \mu \mathrm{m}$ column. Samples were

Table 2: Multiple reaction monitoring (MRM) parameters

\begin{tabular}{lllllllll}
\hline Compound ID & Parent, $\mathbf{m} / \mathbf{z}$ & Daughter, $\mathbf{m} / \mathbf{z}$ & Time, $\mathbf{m s}$ & DP, $\mathbf{V}$ & FP, $\mathbf{V}$ & EP, $\mathbf{V}$ & CE, $\mathbf{V}$ & CXP, $\mathbf{~}$ \\
\hline Bisoprolol & 326.435 & 116.3 & 50 & 46 & 260 & 11 & 27 & 20 \\
\hline
\end{tabular}

DP: Declustering potential, FP: Focusing potential, EP: Entrance potential, CE: Collision energy, CXP: Collision cell exit potential. MRM: Multiple reaction monitoring 
Table 3: Optimized chromatographic conditions

\begin{tabular}{ll}
\hline Parameter & Chromatographic conditions \\
\hline Instrument & $\begin{array}{l}\text { Shimadzu HT (Shimadzu,Japan) LC system } \\
\text { equipped with degasser (DGU-14A), } \\
\text { binary pump (LC-20ADXR) along with } \\
\text { autosampler (SIL-20ACXR) } \\
\text { Discovery C18, 50×2.1 mm, } 5 \mu \mathrm{m} \\
\text { Gradient mode (eluent A [acetonitrile-water-formic } \\
\text { acid, 5:95:0.1 v/v] and eluent B [acetonitrile-formic }\end{array}$ \\
$\begin{array}{ll}\text { Column } \\
\text { Mobile phase } 100: 0.1 \mathrm{v} / \mathrm{v}] \text { ). The initial content of the eluent B is } \\
\end{array}$ & $\begin{array}{l}0 \%, \text { which increases linearly by } 1.0 \text { min to } 100 \% \text { and } \\
1.01 \text { min returns to the initial } 0 \%\end{array}$ \\
$\begin{array}{l}\text { Flow rate } \\
\text { Runtime }\end{array}$ & $2 \mathrm{~min} / \mathrm{min}$ \\
$\begin{array}{l}\text { Column } \\
\text { temperature }\end{array}$ & $30^{\circ} \mathrm{C}$ \\
$\begin{array}{l}\text { Volume of } \\
\text { injection loop }\end{array}$ & $5 \mu \mathrm{l}$ \\
\hline
\end{tabular}

Table 4: Data of A-B permeability for the test and reference compounds (at $10 \mu \mathrm{M}$ )

\begin{tabular}{llllll}
\hline \multirow{2}{*}{ Compound ID } & \multicolumn{4}{c}{ Permeability $\left(\mathbf{1 0}^{-\mathbf{6}} \mathbf{c m} / \mathbf{s}\right)$} & \multirow{2}{*}{ SD $\left(\mathbf{1 0}^{-\mathbf{6}}\right)$} \\
\cline { 2 - 5 } & $\mathbf{1}$ & $\mathbf{2}$ & $\mathbf{3}$ & Mean & \\
\hline Atenolol & 1.83 & 1.99 & 1.48 & 1.77 & 0.26 \\
Propranolol & 37.50 & 35.20 & 35.70 & 36.13 & 1.21 \\
Quinidine & 16.50 & 23.80 & 20.00 & 20.10 & 3.65 \\
Enalapril & 0.62 & 1.39 & 1.93 & 1.31 & 0.66 \\
\hline
\end{tabular}

Each value is represented as a mean \pm SD of 5 observations $(n=5)$, SD: Standard deviation, RSD: Relative standard deviation, ${ }^{\# A c c e p t a n c e ~ c r i t e r i a<~}<2.0$

Table 5: Recovery values

\begin{tabular}{lllll}
\hline Compound ID & \multicolumn{4}{l}{ \% recovery } \\
\cline { 2 - 5 } & $\mathbf{1}$ & $\mathbf{2}$ & $\mathbf{3}$ & Mean \\
\hline Atenolol & 109.61 & 99.70 & 101.90 & 103.74 \\
Propranolol & 112.78 & 97.86 & 97.50 & 102.71 \\
Quinidine & 96.49 & 102.59 & 97.68 & 98.92 \\
Enalapril & 101.73 & 99.13 & 107.20 & 102.69 \\
\hline
\end{tabular}

Each value is represented as a mean \pm SD of 5 observations ( $n=5$ ), SD: Standard deviation, RSD: Relative standard deviation, ${ }^{*}$ Acceptance criteria $<2.0$

chromatographed in a gradient mode (eluent A [acetonitrilewater-formic acid, 5:95:0.1 v/v] and eluent B [acetonitrile-formic acid, 100:0.1 v/v]). The initial content of the eluent B is $0 \%$, which increases linearly by $1.0 \mathrm{~min}$ to $100 \%$ and $1.01 \mathrm{~min}$ returns to the initial $0 \%$. Gradient curve showed in Fig. 2. The mobile phase was delivered at a flow rate of $0.400 \mathrm{ml} / \mathrm{min}$ into the mass spectrometer ESI chamber. The injection volume was $5 \mu$ l. The optimum chromatographic conditions and system suitability parameters are tabulated in Table 3.

Enalapril maleate eluted at $\sim 1.52$ min. Typical multiple reaction monitoring chromatograms of enalapril shown in Fig. 3.

A-B permeability data for the test compound of enalapril maleate and three reference compounds are listed in Table 4.

A-B permeability data for all the reference compounds correspond to the literature data, thus validating this study [14-16]. According to the Caco-2 test results, enalapril showed low permeability. It should be noted that the recovery value (Table 5) for enalapril is $100.62 \%$. Low in vitro permeability data for enalapril are in good agreement with the literature data $\left(0.79-2.29 * 10^{-6} \mathrm{~cm} / \mathrm{s}\right)[17-20]$.

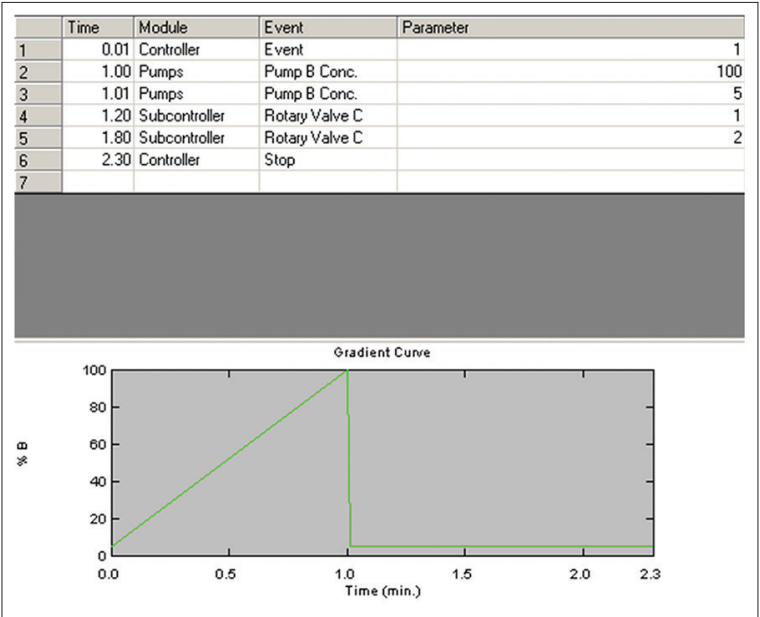

Fig. 2: Gradient curve

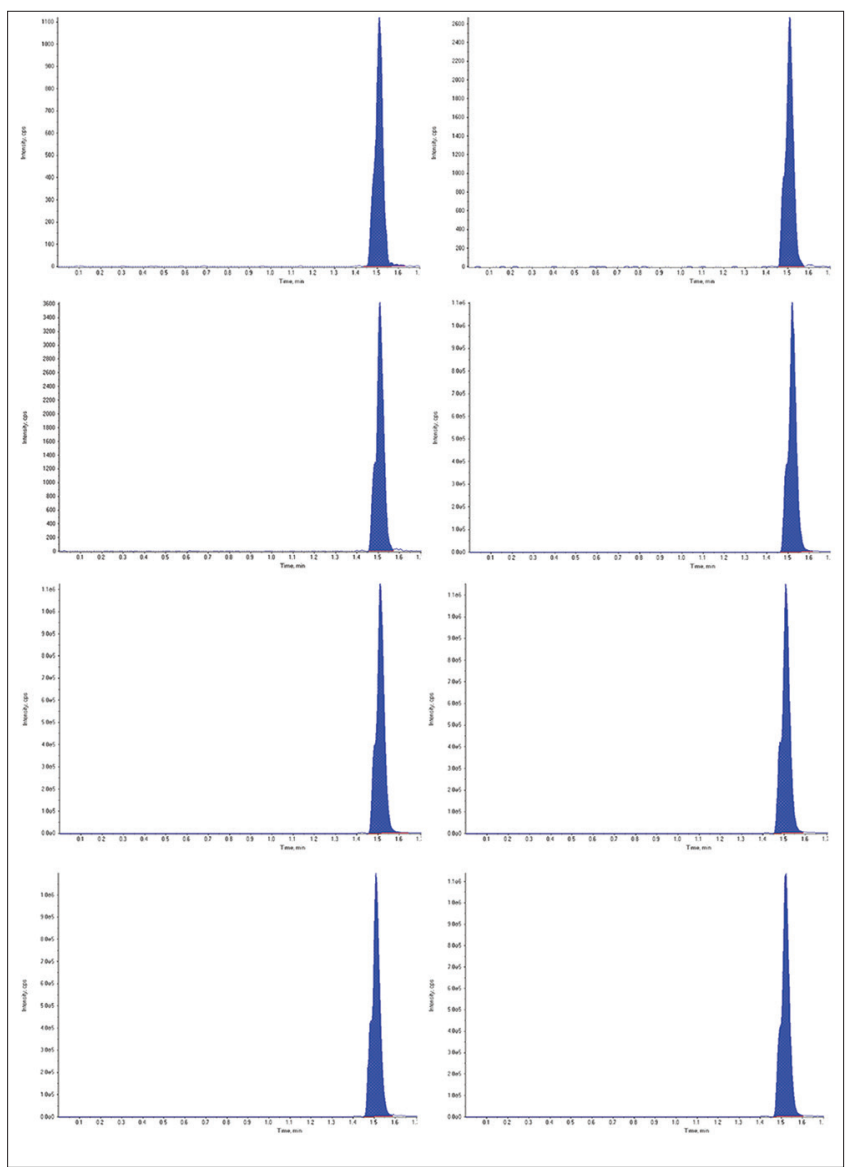

Fig. 3: Typical multiple reaction monitoring chromatograms of enalapril maleate

\section{CONCLUSION}

In summary, it can be concluded that developed method is simple and rapid for determination of enalapril maleate from confluent Caco-2 monolayers and aqueous solution. Acquired results demonstrate that proposed strategy can be effortlessly and advantageously applied for examination of enalapril from Caco-2 cell monolayers.

\section{CONFLICTS OF INTEREST}

The authors declared that they have no conflicts of interest. 


\section{REFERENCES}

1. Ghosh C, Jain I, Shinde CP, Chakraborty BS. Rapid and sensitive liquid chromatography/tandem mass spectrometry method for simultaneous determination of enalapril and its major metabolite enalaprilat, in human plasma: Application to a bioequivalence study. Drug Testing Anal 2012;4:94-103

2. Danafar H, Hamidi M. Liquid chromatography-tandem mass spectrometry (LC-MS) method for the assignment of enalapril and enalaprilat in human plasma. Pharm Biomed Res 2015;1:47-58.

3. Gu Q, Chen X, Zhong D, Wang Y. Simultaneous determination of enalapril and enalaprilat in human plasma by liquid chromatographytandem mass spectrometry. J Chromatogr B Anal Technol Biomed Life Sci 2004;813:337-42.

4. Logoyda L, Korobko D, Oleshchuk O, Proniv T, Dmutriv M. A HPLC MS/MS method development and validation for the simultaneous determination of bisoprolol and enalapril in the present of enalaprilat in human plasma. Int J Appl Pharm 2018;10:31-40.

5. Arena AA, Kamath L, Phillips JE. Development of a Caco-2 drug transport assay in 96-well format. Poster, American Association of Pharmaceutical Sciences, Denver, CO, 2001.

6. Srinivasan B, Kolli AR, Esch MB, Abaci HE, Shuler ML, Hickman JJ. TEER measurement techniques for in vitro barrier model systems. J Lab Autom 2015;20:107-26.

7. Logoyda L, Kondratova Y, Korobko D, Soroka Y. Development of UHPLC method for the determination of captopril in pharmaceutical dosage forms. Asian J Pharm Clin Res 2017;10:308-10.

8. Kondratova Y, Logoyda L, Voloshko Y, Abdel-Megied A, Korobko D, Soroka Y. Development and validation of HPLC-DAD method for the determination of bisoprolol in tablet dosage forms. Int J Appl Pharm 2017;9:54-9.

9. Logoyda L, Abdel-Megied AM, Kondratova Y, Trofimenko O, Korobko D, Dakhym I. Development and validation of HPLC method for the simultaneous determination of enalapril maleate in present of their impurities: Application to tablet analysis. Int J Appl Pharm 2018;10:98-102.

10. Logoyda L, Korobko D, Ivanusa I, Serhii K. Development of the methodology of the chromatographic determination of nifedipine in medicines. Asian J Pharm Clin Res 2017;10:149-52.

11. Liliya L, Dmytro K, Olena S, Ihor B, Tamara K. Development of methodology for identification of captopril in medicines. Asian J Pharm 2016;10:168-71.

12. Kondratova Y, Adebayo T, Logoyda L, Korobko D, Berdey I, Kuchmerovska T. Development of the methodology of the chromatographic determination of amlodipine in medicines. Int J Res Ayurveda Pharm 2016;7:32-5.

13. Polyauk O, Logoyda L. The investigation of conditions of API from group of calcium channel blockers extraction by organic solvents by using high-performance liquid chromatography as assay method. Asian J Pharm Clin Res 2017;10:354-6.

14. Fujikawa M, Ano R, Nakao K, Shimizu R, Akamatsu M. Relationships between structure and high-throughput screening permeability of diverse drugs with artificial membranes: Application to prediction of Caco-2 cell permeability. Bioorg Med Chem 2005;13:4721-32.

15. Gertz M, Harrison A, Houston JB, Galetin A. Prediction of human intestinal first-pass metabolism of 25 CYP3A substrates from in vitro clearance and permeability data. Drug Metab Dispos 2010;38:1147-58.

16. Yazdanian M, Briggs K, Jankovsky C, Hawi A. The "high solubility" definition of the current FDA Guidance on Biopharmaceutical Classification System may be too strict for acidic drugs. Pharm Res 2004;21:293-9.

17. Gozalbes R, Jacewicz M, Annand R, Tsaioun K, Pineda-Lucena A. QSAR-based permeability model for drug-like compounds. Bioorg Med Chem 2011;19:2615-24

18. Hou TJ, Zhang W, Xia K, Qiao XB, Xu XJ. ADME evaluation in drug discovery. 5. Correlation of Caco-2 permeation with simple molecular properties. J Chem Inf Comput Sci 2004;44:1585-600.

19. Yee S. In vitro permeability across Caco-2 cells (colonic) can predict in vivo (small intestinal) absorption in man-fact or myth. Pharm Res 1997;14:763-6.

20. Available from: http://www.cyprotex.com/admepk/in-vitro-permeability/ caco-2-permeability. 